\title{
Привлечение долгового финансирования для средних российских компаний: возможности рынка облигаций
}

\author{
Пашкова Н.А. ${ }^{13}$, Родионов И.И. ${ }^{14}$
}

Российский рынок корпоративных облигаций в большей степени рынок компаний среднего бизнеса. Крупные российские компании, так называемые «голубые фишки» предпочитают западные рынки для размещения долговых обязательств и привлечения синдицированных кредитов, так как объем привлекаемых ресурсов обычно превышает финансовые возможности российских инвесторов. Компании небольших размеров в свою очередь зачастую не имеют доступа к публичным рынкам капитала из-за ограничений достаточности собственного капитала для выпуска ликвидных и востребованных рынком займов. В данном случае ключевым вопросом становится правильное позиционирование средних компании для успешного размещения публичных долговых обязательств и снижения стоимости заимствований. $B$ данной статье рассматриваются факторы, определяющие условия размещения, и возможности по улучшению практики корпоративных заимствований.

Затратами эмитента при привлечении заимствований на публичных рынках капитала являются выплаты купонных платежей и затраты на организацию выпуска. В части затрат на организацию есть фиксированная часть - выплаты регуляторам и другие постоянные платежи, и гибкая часть, на которую компания может повлиять, - комиссия банка-организатора, которая зависит от переговорной силы эмитента, сложности организации и структуры выпуска. Ставка купона формируется исходя из оценки инвесторами кредитного риска компании, премии за дебютное размещение, премии за низкую ликвидность. Оптимизация размещений долговых инструментов и снижение стоимости заимствований рассматривается только в части «гибких затрат» - комиссии банка и доходности бумаг [5]. Доходность рублевых облигаций значительно снизилась за последние несколько лет, существенно увеличив привлекательность рынка облигаций для российских компаний.

\footnotetext{
${ }^{13}$ Магистр экономики, ГУ-ВШЭ.

${ }^{14}$ Профессор, докт. эконом.наук.

Выпуск \#2, 2007
} 
Рисунок 1. Динамика индекса Zetbi-Corp.

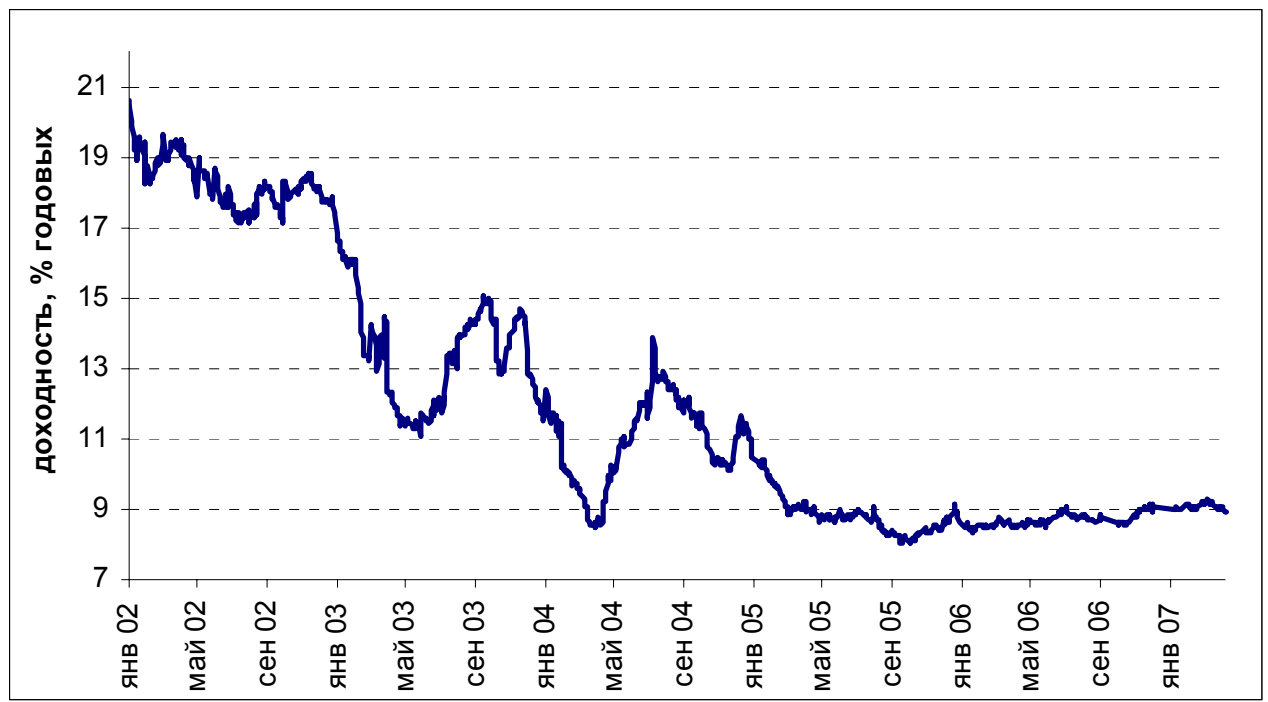

Источник: ИА Cbonds [16]

На ценообразование бумаги и другие условия размещения и обращения облигаций влияет принадлежность ценной бумаги к тому или иному рискованному классу или «эшелону» рынка долгов. Отнесение того или иного актива к определенному рискованному классу на международных рынках решается с помощью кредитных рейтингов. На российском рынке корпоративных облигаций рейтинги имеют менее $20 \%$ бумаг [2], что не позволяет использовать такой простой и эффективный способ «эшелонирования» облигаций. Поэтому для определения «эшелонов» российского рынка корпоративных облигаций принято учитывать множество различных факторов.

\section{Сегмент средних компаний и эшелоны на рынке облигаций}

Рынок рублевых облигаций принято разделять на три «эшелона». Компании среднего бизнеса могут входить как во второй, так и в третий «эшелон» - в зависимости от позиционирования компании и ряда других факторов. Двумя основными факторами при отнесении бумаги к тому или иному «эшелону» служат кредитное качество эмитента и ликвидность облигационного займа [4]. При оценке кредитного качества основными факторами являются $[9,10]$ :

- отраслевая принадлежность компании;

- структура капитала;

- наличие правовых или налоговых рисков;

- наличие и уровень кредитных рейтингов (от международных рейтинговых агентств);

- формат публикуемой финансовой отчетности (МСФО, РСБУ, аудит отчетности);

- финансовое состояние эмитента (уровень долговой нагрузки, рентабельность, динамика развития).

Отраслевая принадлежность эмитента на российском рынке не носит столь однозначного характера для включения в тот или иной «эшелон». Однако отраслевые риски оказывают существенное влияние на кредитное качество эмитентов, а следовательно, можно сделать обобщение об эшелонной 
принадлежности тех или иных отраслей. Так, к первому «эшелону» традиционно относят компании нефтегазовой и энергетической отраслей. Второй «эшелон» более диверсифицирован, к нему, как правило, относят компании из химической и нефтехимической, телекоммуникационной, транспортной, металлургической и машиностроительной отраслей. К третьему «эшелону» чаще всего относят компании строительной, пищевой (АПК) и торговой отраслей.

Рисунок 2. Отраслевая структура рынка корпоративных облигаций в 2006 году (по объему эмиссий)

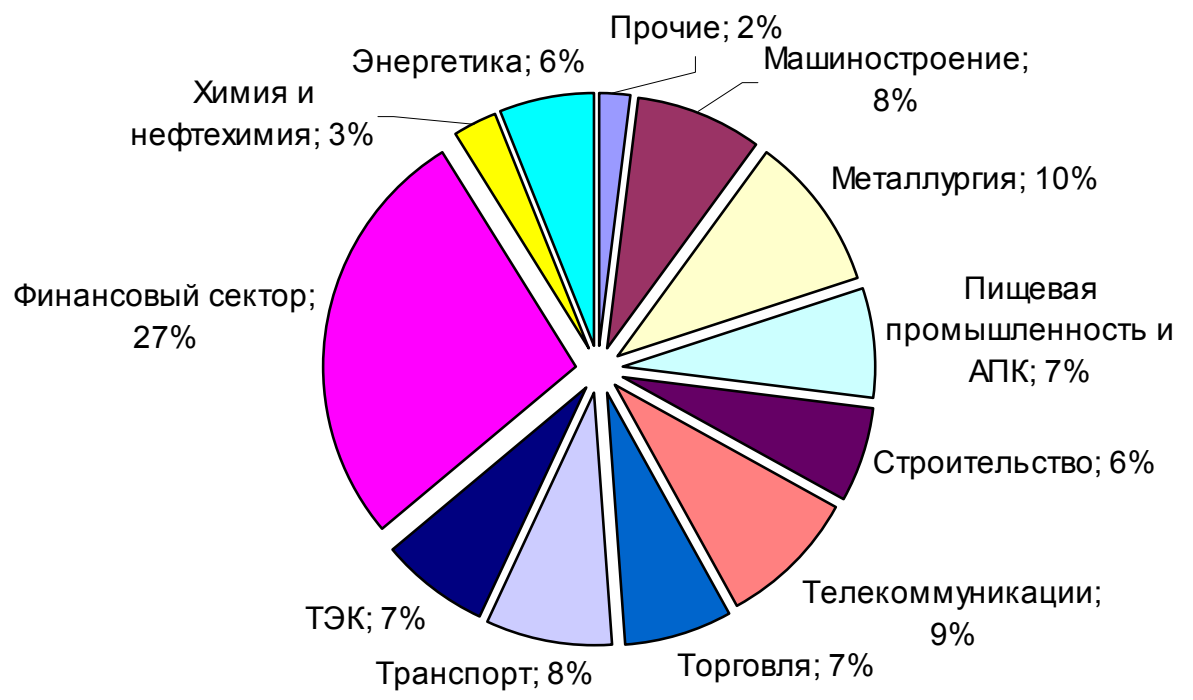

Источник: Cbonds, расчеть автора

Отраслевая структура российского рынка корпоративных облигаций изменялась в сторону большей диверсификации и смещением рынка в сторону банковских заимствований [2]. Если в 2000 году преобладали займы нефтегазового сектора, то уже в 2004 году доля каждого сектора не превышала 20\%. В 2006 году наибольшую долю рынка заняли облигации финансового сектора (27\%), 16\% пришлось на ценные бумаги телекомов, доля остальных отраслей не превышает $10 \%$.

К первому «эшелону», или так называемым «голубым фишкам», относятся облигации крупнейших российских компаний, преимущественно с государственным участием, которые являются системообразующими предприятиями для ряда отраслей экономики. К облигациям первого эшелона в настоящий момент относят выпуски Газпрома, Лукойла, ФСК ЕЭС, РЖД, ТНК и Внешторгбанка. Суммарный объем этих выпусков составляет порядка 80 млрд рублей, что составляет около 15\% рынка корпоративных облигаций. Отличительные черты компаний первого «эшелона» - существенные масштабы бизнеса, хорошие финансовые показатели, в том числе умеренная долговая нагрузка и высокий уровень рентабельности, наличие финансовой отчетности по МСФО, а также кредитных рейтингов от ведущих международных рейтинговых агентств. Риск инвестирования в эти бумаги зачастую определяется как квазисуверенный риск. Кроме того, бумаги первого «эшелона» отличаются высокой ликвидностью, что обеспечивается высокими объемами облигационных выпусков (от 5 млрд рублей). Так, на долю «голубых фишек» приходится около $40-50 \%$ оборота вторичных торгов в корпоративном сегменте. Более того, они входят в ломбардный список Банка России, что позволяет получать рефинансирование под залог данных бумаг для инвесторов. 
Ко второму «эшелону» как правило, относят менее крупные компании по сравнению с «голубыми фишками», однако занимающие лидирующее положение в отрасли или регионе. Большинство данных компаний частные или с ограниченным участием государства. Кредитное качество компаний второго «эшелона» может существенно различаться внутри «эшелона». Сюда входят компании, которые по своим параметрам близки к «голубым фишкам», но имеют ряд особенных рисков, таких как меньший масштаб деятельности и отсутствие государственной поддержки. Обычно к такому «хорошему второму эшелону» относят крупные негосударственные банки и крупных отраслевых лидеров. Также во второй «эшелон» входят компании, достаточно крупные по размеру бизнеса и с хорошей финансовой отчетностью, но имеющие дополнительные факторы риска, такие как отсутствие отчетности по МСФО, отсутствие рейтингов международных рейтинговых агентств, ограничения региона присутствия. Как правило, к таким компаниям относятся ведущие автомобилестроительные, металлургические, машиностроительные и пищевые компании. Достаточно крупные размеры бизнеса и невысокие отраслевые риски повышают инвестиционную оценку данных бумаг. Однако во второй «эшелон» относят также более рискованные компании, которые несут высокие бизнес-риски, характеризуются удовлетворительной финансовой отчетностью, низким уровнем раскрытия информации и отсутствием рейтингов. Положительными факторами оценки данных служит хорошее положение в отрасли, высокие темпы роста и перспективы развития. Ликвидность облигаций второго «эшелона» находится на среднем уровне и сильно зависит от объема выпуска и активности организатора.

К третьему «эшелону» относят так называемые «мусорные облигации» (junk bonds). Первоначально данный термин был введен Майклом Милкеном, известным финансистов 80-х годов XX века. Он подразумевал высокодоходные облигации малоизвестных небольших компаний с низким кредитным качеством и низкой ликвидностью. В настоящее время на международных рынках к «мусорным облигациям» относят бумаги с рейтингом ниже инвестиционного уровня. Так как рейтинг обязательств Российской Федерации находится на второй ступени инвестиционного уровня, то большинство российских компаний даже в случае получения рейтинга попадут в блок junk bonds. Таким образом, на российском рынке критериями отнесения бумаг к «мусорным» мы используем термины, первоначально введенные Милкеном. На российском рынке корпоративных облигаций в третий «эшелон» попадают бумаги с низкой ликвидностью и высокими кредитными рисками эмитента. Как правило, данные компании несу высокие бизнес-риски, отраслевые и правовые риски, занимают второстепенное положение в отрасли, имеют высокую долговую нагрузку и средние размеры бизнеса. Также к третьему «эшелону» относятся небольшие быстрорастущие компании с активной инвестиционной политикой и высокой долговой нагрузкой. Здесь преобладают компании пищевой, торговой, строительной и девелоперской отраслей.

Деление на «эшелоны» на российском рынке весьма условно и проводится каждым инвестором в зависимости от собственных критериев оценки. Однако отнесение компании-эмитента к тому или иному эшелону существенно влияет на уровень ставок заимствований. Позиционирование компании и отнесение к какому-либо эшелону является определяющим для определения параметров и стоимости финансирования.

\section{Ценообразование рублевых корпоративных облигаций}


Исследование рынка рублевых корпоративных облигаций проводится с целью выявления наиболее значимых факторов ценообразования и определения зависимости от них цены/доходности долговых ценных бумаг российских компаний, в том числе компаний среднего бизнеса.

Для анализа ценообразования был выбран период длиной в 19 торговых дней с 05.03.2007 по 30.03.2007, для которого были рассчитаны средние значения спрэдов выпусков корпоративных облигаций. Спрэд ценных бумаг рассчитывался как разница между эффективной доходностью к погашению или к оферте корпоративных облигаций и облигаций города Москвы при соответствующей дюрации. Базовым активом для расчета были выбраны следующие облигации города Москвы:

Таблица 1. Облигации города Москвы, на основе которых рассчитывалась кривая Москвы

\begin{tabular}{|l|c|}
\hline Ценная бумага & Объем эмиссии, рублей \\
\hline Москва-29 & $\mathbf{5 0 0 0} 000000$ \\
\hline Москва-36 & $\mathbf{4 0 0 0 0 0 0 0 0 0}$ \\
\hline Москва-38 & $\mathbf{5 0 0 0} 000000$ \\
\hline Москва-39 & $\mathbf{1 0 0 0 0 0 0 0 0 0 0}$ \\
\hline Москва-40 & $\mathbf{5 0 0 0 0 0 0 0 0 0}$ \\
\hline Москва-41 & $\mathbf{1 0 0 0 0 0 0 0 0 0 0}$ \\
\hline Москва-42 & $\mathbf{5 0 0 0} 000000$ \\
\hline Москва-44 & $\mathbf{2 0 0 0 0 0 0 0 0 0 0}$ \\
\hline Москва-47 & $\mathbf{1 0 0 0 0 0 0 0 0 0 0}$ \\
\hline Москва-48 & $\mathbf{3 0 0 0 0} 000000$ \\
\hline
\end{tabular}

\section{Выборка исследования}

Объектом исследования в данной работе выступают рублевые облигации российских компаний. Для определения выборки корпоративных облигаций основным критерием была выбрана ликвидность обращения ценных бумаг, как фактор эффективного рыночного ценообразования [3]. Цены и доходность низколиквидных бумаг не отражают реальной оценки рынком справедливой стоимости, а зачастую являются индикативными котировками организатора/маркетмейкера выпуска или других участников рынка. Поэтому в проводимом исследовании выборка анализируемых выпусков корпоративных облигаций, не включающих бумаги банковского и финансового секторов, ограничивается высоколиквидными бумагами для получения релевантных результатов.

Выявление наиболее ликвидных корпоративных облигаций было произведено по результатам анализа торгов на ММВБ за I квартал 2007 года. Критериями выбора были выбраны показатели объема торгов в рублях в режиме основных сделок, переговорных сделок и сделок РЕПО и количества сделок за период [3]. В итоге было выбрано 70 ценных бумаг 70 эмитентов, суммарный объем которых составил 186192595000 рублей, что составляет порядка 43,53\%

\section{Выпуск \#2, 2007 \\ (c) Электронный журнал Корпоративные Финансы, 2007}


суммарного объема рынка рублевых корпоративных облигаций российских эмитентов. В выборке представлены по одному выпуску каждого эмитента вне зависимости от ликвидности торгов ценных бумаг, так как факторы ценообразования всех выпусков одного эмитента являются одинаковыми. Суммарный объем торгов в основном режиме за 1 квартал 2007 года выбранных бумаг составил 44296297968 рублей, или 52,97\% общих торгов рынка за указанный период, а количество сделок составило 17 626, то есть 39,24\% рынка.

Дополнительным критерием выбора ценных бумаг послужила отраслевая принадлежность компаний-эмитентов. Для выявления влияния отраслевых рисков на ценообразование ценных бумаг необходимо включение в выборку нескольких компаний в каждой отрасли, различных по кредитному качеству и объему выпусков. В результате в выборке оказались компании-эмитенты следующих отраслей:

- топливно-энергетический комплекс (ТЭК), в который вошли компании нефтегазовой отрасли в количестве 5 и 1 топливно-сервисная компания;

- энергетика (7 компаний);

- химия и нефтехимия (6 компаний);

- транспорт, в который вошло 4 компании, одна из которых - РЖД с займом на 10 млрд рублей, и остальные три компании авиатранспорта с невысокой ликвидностью были добавлены для увеличения репрезентативности выборки;

- телекоммуникации (6 компаний);

- торговля (11 компаний);

- металлургия и горнодобывающая промышленность (6 и 1 компании соответственно);

- машиностроение (8 компаний);

- АПК и пищевая промышленность (2 и 4 компании соответственно);

- строительство и промышленность строительных материалов (4 и 3 компании соответственно);

- легкая промышленность (2 компании).

Объем эмиссии рассматриваемых компаний варьируется от 750 млн до 10 млрд рублей с максимальным сроком погашения 12.09.2013 и сроком обращения от 2 до 7 лет. Доля суммарного объема эмиссий каждой отрасли не превышает $15 \%$, минимальный объем составляет $1,5 \%$ у выпусков компаний легкой промышленности наибольшую долю занимают эмиссии компаний энергетики, ТЭКа, торговли и телекоммуникаций, что связано с большими объемами эмиссий компаний данных отраслей. По объему торгов доля каждой отрасли не превышает $15,5 \%$, а минимальный объем занимает $4,3 \%$ у выпусков компаний легкой промышленности.

\section{Отраслевой фактор}

Для начала попытаемся понять, насколько ценообразование рублевых облигаций зависит от отраслевой принадлежности эмитента. Наименьшие спрэды наблюдаются в отрасли телекоммуникаций - в среднем 159 базисных пунктов, в отрасли энергетики - 202 базисных пунктов . Также низкие спрэды наблюдаются в облигациях нефтегазовой отрасли - 277 базисных пунктов. Следует отметить, что в данных секторах преобладают крупные компании преимущественно с государственным участием, что относится к отраслям ТЭК и энергетики в первую очередь. Многие облигации относятся инвесторами к «голубым фишкам», что определяет отнесение данных отраслей к первому «эшелону» российского рынка 
корпоративных облигаций, спрэд по которым мы ограничиваем в диапазоне от 0 до 300 базисных пунктов к кривой облигаций города Москвы. Можно сделать вывод, что наиболее низкая стоимость финансирования на рынке рублевых облигаций присуща компаниям, формирующим базовые отрасли экономики и характеризующимся насыщением и умеренным развитием рынка, являющимся во многом инфраструктурными, и создающим предпосылки для развития других отраслей.

Рисунок 3. Ценообразование корпоративных облигаций по отраслевым группам

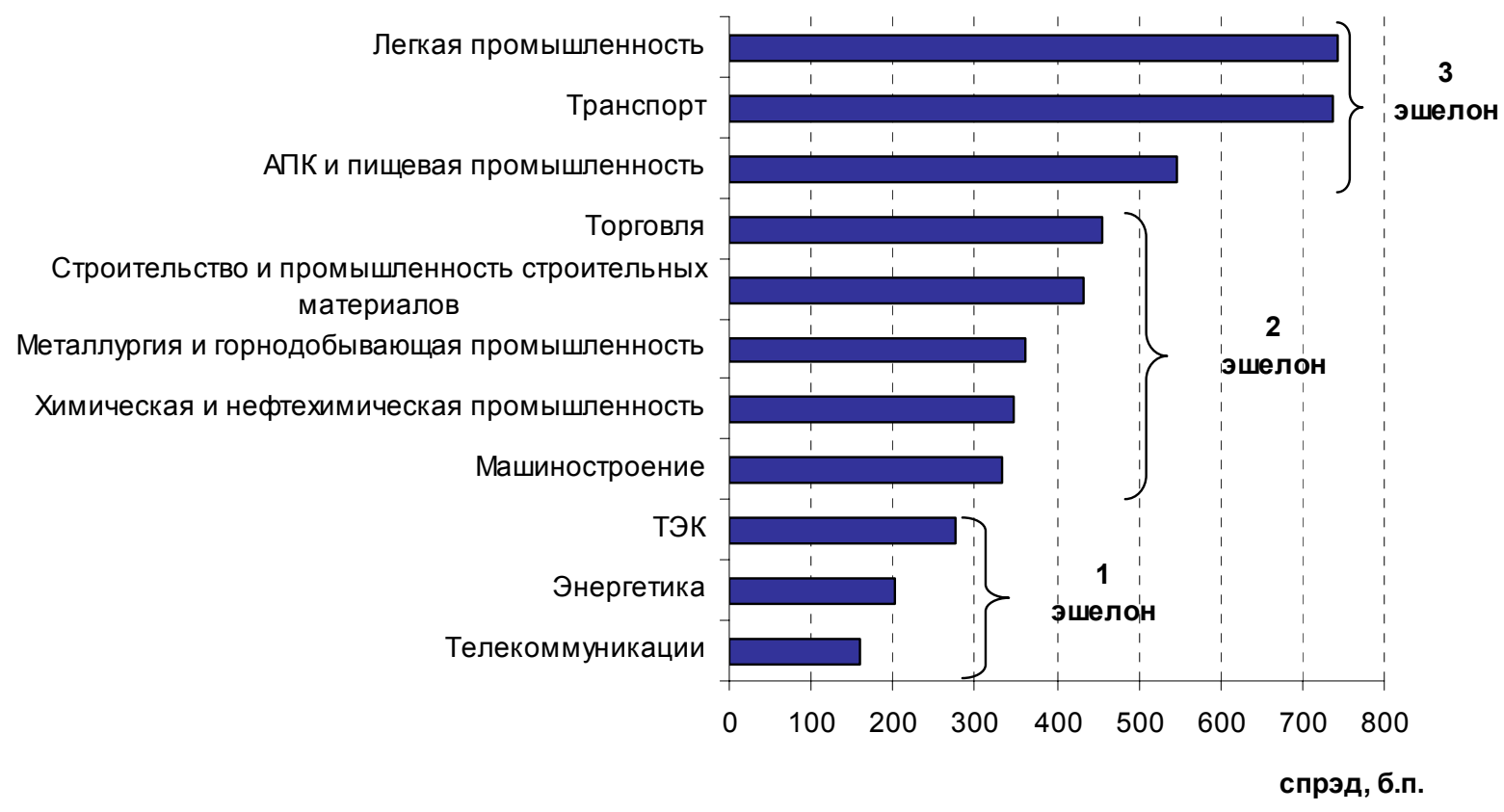

Источник: расчеты автора

В ценовом диапазоне от 300 до 500 базисных пунктов оказалось большинство ценных бумаг. Средний спрэд облигаций отрасли машиностроения 333 базисных пунктов, химии и нефтехимии - 348 базисных пунктов, металлургии и горнодобывающей промышленности - 361 базисных пунктов, строительства и промышленности строительных материалов - 433 базисных пунктов , торговли 455 базисных пунктов . Выпуски компаний - представителей вышеназванных отраслей - традиционно относятся ко второму эшелону рынка рублевых облигаций. Важно отметить, что три вышеуказанные отрасли -машиностроение, химия и нефтехимия и металлургия - с рядом оговорок можно назвать инфраструктурными, так как компании в данных отраслях производят то, что обеспечивает функционирование инфраструктурных отраслей и то, что фактически является сырьем для практически всех остальных отраслей промышленности. Две другие отрасли - строительство и торговля - характеризуются высокими темпами развития и существенными отраслевыми рисками, что и определяет их более высокий уровень доходности.

Наибольшие спрэды (от 500 до 800 базисных пунктов ) наблюдаются по облигациям компаний АПК и пищевой промышленности - 548 базисных пунктов , транспорта - 737 базисных пунктов , и легкой промышленности - 743 базисных пунктов . Особенностью данных отраслей, по сравнению с предыдущими, является то, что они производят конечный продукт или предоставляют услуги как в транспортной отрасли, ориентированные непосредственно на потребителя, индивидуального или корпоративного, что несет в себе риски, связанные с 
маркетингом и продажами продукции. В случае компаний АПК и легкой промышленности дополнительным фактором, обуславливающим высокие спрэды по их облигациям, является непрозрачность корпоративной структуры, характерная для многих компаний данных отраслей. В случае же транспортной отрасли, не считая РЖД, которая традиционно относится к «голубым фишкам», в анализ попали в основном авиакомпании, крайне негативным фактором ценообразования которых является низкий уровень конкурентоспособности отрасли в целом.

Однако данное деление не является жестким, дифференциация по эшелонам наблюдается и внутри секторов. Так, говоря о нефтегазовом комплексе, необходимо отметить, что в нем присутствуют как эмитенты первого эшелона - Газпром и «Лукойл», так и эмитенты второго эшелона - НОВАТЭК, «Татнефть». Крайне высока дифференциация и в металлургической отрасли. В частности, выпуски облигаций таких компаний, как ОМК, ТМК и СГ «Мечел», вполне можно отнести к «нижней границе» второго эшелона, тогда как бумаги «Инпрома» и «Тулачермета» по ряду параметров можно отнести к третьему эшелону.

Общий вывод относительно влияния отраслевой принадлежности эмитента на позиционирование его облигаций в целом можно свести к следующему: энергетическим и ресурсным секторам экономики соответствует более высокий эшелон; секторам, ориентированным на конечного потребителя, - более низкий. Или, другими словами, принадлежность облигационного выпуска к тому или иному эшелону зависит от инфраструктурной значимости ее эмитента для российской экономики в целом. В действительности текущая структура российской экономики предполагает большую устойчивость базовых, инфраструктурных отраслей, характеризующихся наименьшей степенью переработки, что находит отражение и в ценообразовании рублевых облигаций.

Наличие дифференцированного ценообразования облигаций внутри однородных отраслевых групп указывает на необходимость детального анализа эмитентов с целью отнесения их облигационных займов к тому или иному эшелону рублевых облигаций.

\section{Рейтинг финансового состояния эмитента}

Для целей анализа финансовых показателей эмитентов авторами был разработан рейтинг финансового состояния по шкале от 0 до 100 пунктов (или от D до $\mathrm{A}+)$ в буквенном выражении:

Таблица 2. Рейтинг финансовых показателей эмитента.

\begin{tabular}{|ll|}
\hline $\mathrm{A}+$ & $90-100$ \\
$\mathrm{~A}$ & $80-90$ \\
$\mathrm{~A}-$ & $70-80$ \\
$\mathrm{~B}+$ & $60-70$ \\
$\mathrm{~B}$ & $50-60$ \\
$\mathrm{~B}-$ & $40-50$ \\
$\mathrm{C}+$ & $30-40$ \\
$\mathrm{C}$ & $20-30$ \\
$\mathrm{C}-$ & $10-20$ \\
$\mathrm{D}$ & $0-10$ \\
\hline
\end{tabular}

Данный рейтинг оценивает эмитентов по пяти компонентам финансового состояния: размер бизнеса (вес 0,4), структура капитала и уровень долговой нагрузки (вес 0,4), уровень рентабельности (вес 0,1$)$, уровень ликвидности (вес 0,05$)$ и динамика развития (вес 0,05). Веса выбраны по результатам регрессии 
зависимости спрэда от финансовых показателей, а также экспертной оценки $[7,11]$. Использовались следующие финансовые показатели: выручка компании, активы, операционная рентабельность, рентабельность EBITDA, выручка/долг, долг/активы, долг/EBITDA, текущая ликвидность, рост выручки годовой.

(1) $\quad \mathrm{SP}=\mathrm{C}(1)+\mathrm{C}(2) \mathrm{X} 1+\mathrm{C}(3) \mathrm{X} 2+\mathrm{C}(4) \mathrm{X} 3+\mathrm{C}(5) \mathrm{X} 4+\mathrm{C}(6) \mathrm{X} 5$

$\mathrm{SP}$ - средний спрэд доходности облигаций каждого эмитента

Регрессоры:

$\mathrm{X} 1$ - размер бизнеса,

Х2 - рентабельность,

Х3- долговая нагрузка,

Х4 - темп роста,

Х5 - ликвидность.

Каждый регрессор представляет оценку вышеперечисленных параметров по нескольким финансовым показателям. Регрессоры были нормированы.

Далее строились регрессии без ряда регрессоров. Наиболее значимой регрессией (по R squared) оказалась следующая регрессия:

(2) $\mathrm{SP}=\mathrm{C}(1)+\mathrm{C}(2) \mathrm{X} 1+\mathrm{C}(4) \mathrm{X} 3$

что подтверждает определяющую значимость размеров компании и долговой нагрузки для оценки доходности долговых обязательств инвесторами.

\section{Результаты регрессии:}

Dependent Variable: SP

Method: Least Squares

Date: 04/29/07 Time: 00:24

Sample: 170

Included observations: 70

\begin{tabular}{lrlrr}
\hline \hline \multicolumn{1}{c}{ Variable } & Coefficient & \multicolumn{1}{c}{ Std. Error } & t-Statistic & Prob. \\
\hline \hline \multicolumn{1}{c}{ X1 } & -0.106375 & 0.038566 & -2.758280 & 0.0086 \\
X3 & 0.121183 & 0.194897 & 1.101417 & 0.0917 \\
C & 440.0880 & 83.85380 & 5.248277 & 0.0000 \\
\hline \hline R-squared & 0.158928 & Mean dependent var & 413.1205 \\
Adjusted R-squared & 0.117901 & S.D. dependent var & 211.9759 \\
S.E. of regression & 199.0880 & Akaike info criterion & 13.49112 \\
Sum squared resid & 1625078. & Schwarz criterion & 13.61277 \\
Log likelihood & -293.8046 & F-statistic & 3.873669 \\
Durbin-Watson stat & 1.410411 & Prob(F-statistic) & 0.028779
\end{tabular}

Затем строилась регрессия на основе зависимости спрэда от рейтинга компании.

(3) $\quad \mathrm{SP}=\mathrm{C}(1)+\mathrm{C}(2) \mathrm{R}$

$\mathrm{SP}$ - средний спрэд доходности облигаций каждого эмитента.

Регрессоры:

$\mathrm{R}$ - рейтинг компании (от 0 до 100 баллов).

Результаты регрессии:

Dependent Variable: SP 
Method: Least Squares

Date: 04/30/07 Time: 08:52

Sample: 170

Included observations: 70

\begin{tabular}{lrlrr}
\hline \hline \multicolumn{1}{c}{ Variable } & Coefficient & \multicolumn{1}{c}{ Std. Error } & t-Statistic & Prob. \\
\hline \hline \multicolumn{1}{c}{ R } & -0.267472 & 0.091957 & -2.908672 & 0.0058 \\
$\mathrm{C}$ & 461.0179 & 33.78468 & 13.64577 & 0.0000 \\
\hline \hline R-squared & 0.167664 & Mean dependent var & 413.1205 \\
Adjusted R-squared & 0.147846 & S.D. dependent var & 211.9759 \\
S.E. of regression & 195.6795 & Akaike info criterion & 13.43522 \\
Sum squared resid & 1608200. & Schwarz criterion & 13.51632 \\
Log likelihood & -293.5749 & F-statistic & 8.460373 \\
Durbin-Watson stat & 1.413719 & Prob(F-statistic) & 0.005779 \\
\hline \hline
\end{tabular}

В итоге регрессия значима на уровне R squared $16,77 \%$ и F-статистики 8,46.

\section{Результаты исследования}

Согласно проведенному регрессионному анализу, средний уровень спрэдов для облигаций 1-го эшелона, то есть облигаций, эмитенты которых имеют рейтинг от «A-» до «A+», составляет порядка 50-200 базисных пунктов , бумаги второго эшелона (рейтинг от «В-» до «B+») торгуются со спрэдом от 200 до 400 базисных пунктов , а спрэды выпусков третьего эшелона (рейтинг эмитентов ниже «С+»), как правило, превышают 400 базисных пунктов.

Рисунок 4. Доходности рублевых корпоративных облигаций на основе анализа финансовых показателей

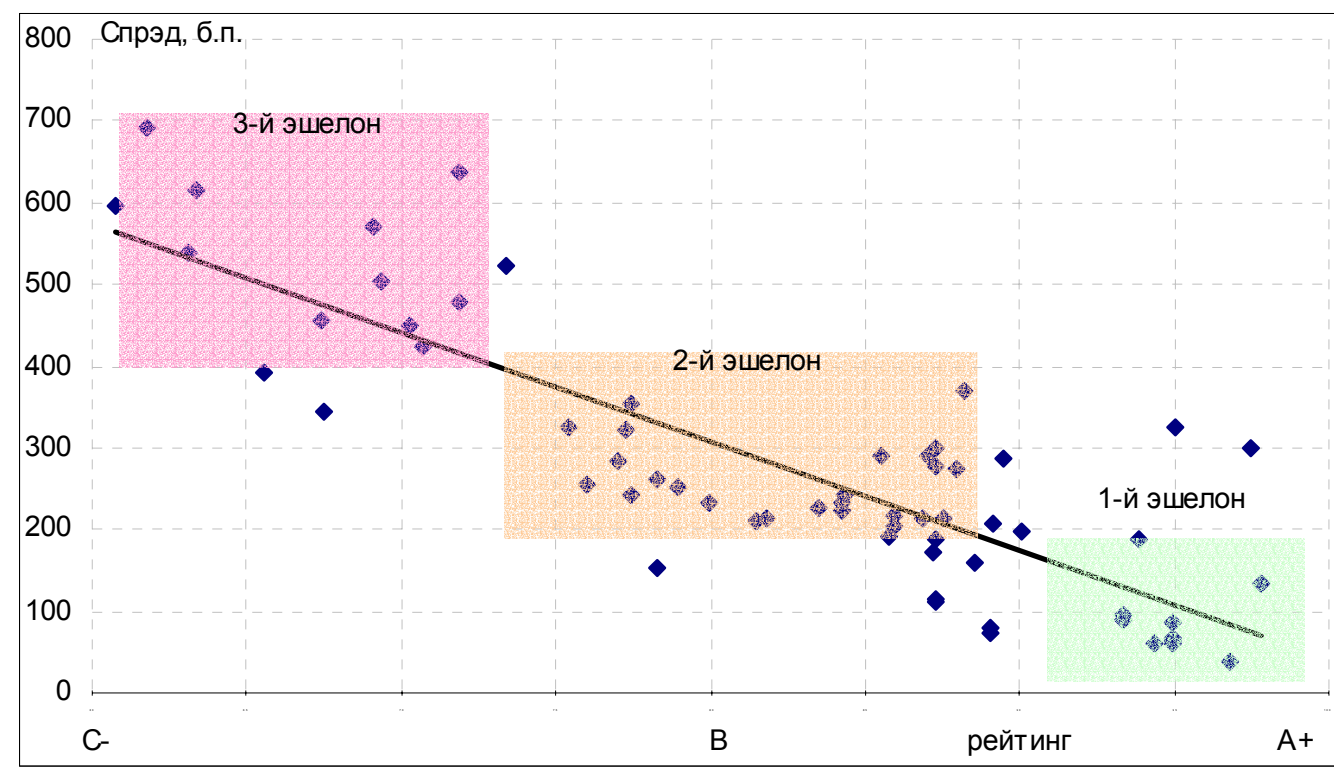

Источник: расчетьл автора

Безусловно, эшелонирование и оценка справедливого уровня спрэдов рублевых облигаций на основании только их финансовой отчетности имеют ряд 
существенных ограничений, связанных прежде всего с характером исходной информации. Несовершенство бухгалтерского учета и российского законодательства позволяет не отражать в финансовой отчетности действительное финансовое положение компании, что снижает привлекательность представленного подхода. Тем не менее использование финансовых показателей эмитентов для эшелонирования и ценообразования рублевых облигаций имеет смысл, поскольку позволяет оценивать сравнительную привлекательность компаний - представителей различных отраслей.

Дополнительными факторами ценообразования долговых ценных бумаг помимо финансовых показателей являются корпоративное управление и стратегия компании на финансовых рынках [12]. Характерными признаками эмитентов с качественным корпоративным управлением является наличие отчетности по МСФО, своевременное ее представление, четкие и ясные цели облигационного займа, наличие аудиторского заключения о деятельности компании, свободный доступ к интересующей информации инвесторов, наличие рейтинга международных рейтинговых агентств $[8,15]$. Справедливое ценообразование, в свою очередь, зависит от эффективности рынка ценных бумаг, которая также характеризуется информационной прозрачностью. Таким образом, рекомендацией эмитентам для снижения стоимости заимствований на публичных рынках служит создание четкой и ясной стратегии поведения на финансовых рынках, повышение качества корпоративного управления и максимизация транспарентности.

В перспективе структура рынка рублевых корпоративных облигаций будет изменяться в сторону более высокой степени дифференциации эмитентов по кредитному качеству при формировании двух ключевых сегментов инвестиционного и спекулятивного. Данное изменение будет связано с увеличением выхода на рынок облигаций все большего количества компаний низкого кредитного качества, которым необходимо в первую очередь рефинансировать существующие долги и которых привлекает высокая рыночная ликвидность. С другой стороны, произойдет переоценка рисков компаний «второго» эшелона, что приведет к сужению спрэдов в рамках второго эшелона. Задачей компаний среднего бизнеса становится, таким образом, устойчивое вхождение во второй эшелон инвестиционный сегмент российского рынка облигаций.

\section{Список использованных источников:}

1. Федеральный закон «О рынке ценных бумаг» от 22.04.1996 г. № 39-Ф3.

2. Архипов А. Анализ структуры рынка рублевых долговых обязательств и ее прогноз // Рынок ценных бумаг. Рынок долгов. Россия Выпуск 4. 2006

3. Лобанов А.А. Энциклопедия финансового риск-менеджмента. 2-е изд., испр. и доп. М.: Альпина Паблишер. 2005. - 878 с.

4. Твардовский В.В. Риски эмитента и ожидаемая доходность облигаций // Рынок ценных бумаг, 2006. № 5.

5. Корпоративные облигации: Структура и анализ / Ричард С. Уилсон, Фрэнк Дж. Абоцци. Пер. с англ. М.: Альпина Бизнес Букс, 2005. - 445 с.

6. Wild J.J., Subramanyan K.R. Financial Statement Analysis. McGraw Hill: Irwin, 2004. $-559 \mathrm{p}$.

7. Black F., Scholes M. The pricing of options and corporate liabilities // Journal of Political Economy, 1973. № 81.

8. Bris A., Ivo Welch. The optimal concentration of creditors // NBER Working papers №. 8652, December 2001. 
9. Elton E., Gruber M., Agrawal D., Mann C. Explaining the rate spread on corporate bonds // Journal of Finance, 2001. № 56 (1), pp. 247-277.

10. Estrella A. Credit Ratings and Complimentary Sources of Credit Quality Information // Basel Committee on Banking Supervision, 2000. №2.

11. Jorion P. Financial Risk Manager Handbook (FRM), 2d ed. John Wiley \& Sons, Inc. 2003. $-\mathrm{p} / 701$.

12. Kaplan S.N. Berk A. Sensoy,Per Stromberg/ What are firms? Evolution from birth to public companies // NBER Working papers \# 11581, August 2005/

13. Kwon K. O. A simple continuous measure of credit risk // Lund University: Working papers, 2003. № 14.

14. Wayne L. Credit Raters Get Scrutiny and Possibly a Competitor // New York Times. 2002. - p. C1.

15. Woojin Kim, Weisbach M.S. Do firms go public to raise capital? // NBER Working papers № 11197, March 2005.

16. http://www.cbonds.info - Информационно-аналитическое агентство.

17. http://www.cbr.ru - Официальная страница ЦБ РФ.

18. http://www.micex.ru - Официальная страница ФБ ММВБ. 